\title{
La imagen de la etnografía: El uso de la fotografía en el trabajo de campo
}

\author{
Eleder Piñeiro Aguiar ${ }^{1}$ e Carlos Diz ${ }^{1}$ \\ ${ }^{1}$ Departamento de Sociología y Comunicación, Facultad de Sociología, Universidade da \\ Coruña, España | elederpa1983@gmail.com; carlos.diz@udc.es | https://orcid.org/0000- \\ 0001-6770-7180; https://orcid.org/0000-0002-9753-7730
}

Resumen: En este ensayo exponemos una relación entre las imágenes y la teoría antropológica que da respuesta a algunos debates contemporáneos de la antropología social, centrándonos principalmente en la denominada crisis de la autoridad etnográfica. Entendemos que tal análisis contribuye a la discusión sobre el compromiso ético y epistemológico del trabajo de campo. Nuestro objetivo principal es discutir varias aproximaciones históricas al trabajo de campo a través del uso de imágenes, interrogando la relación entre el uso de la fotografía en la investigación y la imagen de la etnografía como método y práctica. Mediante el análisis interpretativo-hermenéutico de diversas fotografías procedentes tanto de textos clásicos de la antropología como de otros más actuales nos proponemos, en segundo lugar, esclarecer las relaciones de identidad/alteridad y las repercusiones que ha tenido la antropología en comprender al "otro", entendiendo esta relación como una relación ético-política, además de científico-epistemológica. Los resultados permiten observar, a través de estas imágenes, cómo la muerte del autor y la crisis del trabajo de campo clásico generan nuevas formas de entender la realidad que conllevan una invención, una emoción y una imaginación etnográfica diferentes y en consonancia con los nuevos tiempos. Es en este sentido en el que proponemos nuestro concepto de desenfoque visual etnográfico, abriéndonos a nuevos debates teórico-metodológicos, subrayando la potencialidad de la antropología visual y descentrando y pluralizando nuestra mirada investigadora. Como conclusión, este trabajo critica cualquier esencialismo, remarcando que no existe una mirada pura ni neutral, y que toda investigación es vulnerable a la mirada de otros.

Palabras clave: Antropología Visual; Imagen; Cultura; Otredad.

\section{The Image of Ethnography: The Use of Photography in Fieldwork}

\begin{abstract}
In this essay we expose a relationship between images and anthropological theory that responds to some contemporary debates in social anthropology, focusing on the so-called crisis of ethnographic authority. We understand that such an analysis contributes to the discussion on the ethical and epistemological commitment of fieldwork. Our main objective is to discuss various historical approaches to fieldwork through the use of images, interrogating the relationship between the use of photography in research and the image of ethnography as method and practice. Through the interpretative-hermeneutic analysis of various photographs and images from classic anthropological texts, we propose, secondly, to clarify the relations of identity/alterity and the repercussions that anthropology has had in understanding the "other," understanding this relation as an ethical-political relation, as well as a scientificepistemological one. The results allow us to observe, through these images, how the death of the author and the crisis of classical ethnographic fieldwork generate new ways of understanding reality that entail an invention, an emotion and an ethnographic imagination different and in line with the new times. It is in that sense that we propose our concept of ethnographic visual blur, opening ourselves to new theoretical-methodological debates, underlining the potential of visual anthropology, and decentring and pluralising our research gaze. In conclusion, this work criticises any essentialism, remarking that there is no such thing as a pure gaze and that all research is vulnerable to the gaze of others.
\end{abstract}

Keywords: Visual Anthropology; Image; Culture; Otherness.

\section{Introducción}

En un siglo XIX impregnado de positivismo y de teorizaciones evolucionistas, la naciente antropología era llamada a comprender la diversidad cultural lejos de la metrópoli y a conocer cómo había ido formándose el pasado de la humanidad hasta llegar al culmen del progreso, aparentemente representado por la industrializada Inglaterra victoriana. 
Dice Clifford (1995) que el antropólogo fue el último en llegar, pues por los lugares donde se comenzaron a asentar los primeros etnógrafos, en las primeras dos décadas del siglo XX, habían pasado soldados, misioneros, administradores coloniales, comerciantes... Entre ambas épocas, lo que se llamó en un primer momento "antropología de salón" y después "época clásica del trabajo de campo", se produjo el despegue de la disciplina, para lo cual se conformó un método que ha sido "imagen de marca" de la Antropología y un rito de paso necesario para la consolidación de numerosos antropólogos/as: el trabajo de campo etnográfico, basado en observación participante.

En este texto nos centraremos en el influjo que lo visual, y en concreto la fotografía, ha tenido para la Antropología, destacando algunos momentos en su desarrollo en base a la selección de fotografías que consideramos verdaderos estudios de caso e iconos disciplinares. Por esta razón, las dos primeras imágenes (fig. 1 y 2) han sido elegidas debido a su popularidad y a su fuerte impacto en la antropología, para relacionarlas con debates que se han dado en la disciplina. Pero a raíz de estos debates y de la situación actual, las imágenes se difuminan, hablan, interpelan y complejizan el concepto de público, el cual es ahora interpelado por las obras, que ya no solo son vistasosori sino que también nos miran; todo ello en paralelo a la ruptura de la autoridad etnográfica. Motivo por el cual nuestra selección de fotografías se amplía con otras dos imágenes (fig. 3 y 4) que "descentran" las imágenes clásicas de la disciplina y se abren a nuevos enfoques y a nuevos horizontes antropológicos.

Nuestro punto de partida es que la mediación que supone la cámara ha sufrido un proceso de ruptura desde la denominada "crisis de la autoridad etnográfica", aquella que pone de manifiesto que quien investiga ya no es un sujeto omnisciente sino uno más en el campo, que puede ser interpelado, discutido, mirado, puesto en duda (Clifford y Marcus, 1991; Fox, 1991). En consecuencia, surge lo que aquí denominamos desenfoque visual etnográfico. Con este término queremos hacernos eco de dos factores fundamentales para el desarrollo de lo visual y su análisis como metodología para una mejor comprensión de lo cultural: la repercusión que la denominada "muerte del autor" (Barthes, 1987; Foucault, 1987) ha tenido para la Antropología, y el descentramiento que supone el cambio en las relaciones de identidad/alteridad desde los años 70 , con el peso que ha tenido lo poscolonial, las luchas por los derechos civiles, el antibelicismo, los feminismos, la negritud y los cambios tecnológicos. Para ello, utilizamos un marco teórico interpretativo que bebe, por una parte, de las repercusiones del debate Adorno-Benjamin en torno a la obra de arte y la reproductibilidad técnica (Aznar y López Díaz, 2019); y por otra parte una perspectiva interpretativa-hermenéutica con relaciones con lo decolonial, para preguntar y tratar de responder lo siguiente: ¿cómo la antropología imagina al "otro"?, ¿cuál es el espejo ante el que esta disciplina se mira?, ¿cómo la etnografía (re)produce la otredad? y ¿qué otras miradas y enfoques interpretativos pueden acompañar las discusiones antropológicas contemporáneas?

\section{Metodología}

Este texto forma parte de una línea de investigación donde la estética y lo artístico, entendidos en clave política, viene siendo trabajada desde diversos enfoques: fotografía y su relación con la identidad cultural (Molina y Piñeiro, 2017); performance y exilio migrante (Alfonso y Piñeiro, 2016); estética y política en zonas fronterizas (Alfonso y Piñeiro, 2021); y arte político y movimientos sociales (Diz, 2011).

Para la realización de dichos trabajos y del que ahora presentamos nos reconocemos herederos del interpretativismo y la hermenéutica que recorre la línea desde Nietzsche a Foucault y que en Antropología ha tenido resonancias desde la escuela interpretativista (Geertz, 2000; Lisón Tolosana, 2001). Por su parte, la herencia de Heidegger lleva 
a una concepción de las relaciones sujeto-objeto, al entender la objetividad como intersubjetividad, lo que, a su vez, había de llevarles [a los hermeneutas] a una atención preferente por ese fenómeno primordialmente intersubjetivo que es el lenguaje y al intento de acceder al sujeto no por la "vía corta" de la conciencia, sino a través del rodeo de sus sedimentaciones objetivadas en los documentos de la cultura (Gómez, 2002, p. 12).

La selección de obras aquí comentadas busca poner de manifiesto cómo la imagen puede poner de relieve aspectos de la realidad que la mera descripción etnográfica no nos brinda suficientemente. En otras palabras, lo que proponemos es la defensa de una interpretación mixta, a caballo entre la narración y el visionado de imágenes, que condense aspectos clave de la historia de la antropología, así como nuevos dilemas y aproximaciones, a saber: el debate en torno a la autoridad etnográfica, el influjo del feminismo o la crítica decolonial, entre otros.

Para ello recogemos algunas obras aparecidas en trabajos clásicos de la disciplina y otras más actuales, y las hacemos hablar, a la vez que nos dejamos llevar por la consideración de Didi-Huberman et al. (2007), según la cual las imágenes no solo las miramos, sino que también nos miran. Para el análisis, separamos dos momentos de la genealogía de la disciplina: uno clásico, en torno a la aparición del trabajo de campo como método; y otro más actual, con las repercusiones que el interpretativismo y la crítica (de)colonial han venido generando en las últimas décadas.

\section{Primeras imágenes: el shock etnográfico}

A decir de Walter Benjamin (1989, p. 75), "todos tenemos derecho a ser filmados". El autor se hacía eco de los cambios técnicos producidos entre finales del siglo XIX y principios del $X X$, exponiendo que en esa época de reproductibilidad técnica las obras de arte pierden su aura por cuanto el "aquí" y el "ahora" son desconfigurados. Además del cine, hablaba del poder de la fotografía para llevar a cabo una revelación masiva que conectase con las masas obreras frente a la estética política del fascismo, para el cual era tan importante la representación del poder como el poder de la representación (Balandier, 1994). Observemos que es en esa época cuando la Antropología recogía todo un sinnúmero de objetos materiales de diversas procedencias, extirpadas de su "aquí" y su "ahora" en un proceso de extractivismo colonial económico, epistémico y ontológico (Grosfoguel, 2016), elaborando una misión archivística y museística (Clifford, 1995); además, los primeros trabajadores de campo estaban obligados a aportar muestras de primera mano: notas, grabaciones y fotografías de los pueblos estudiados.

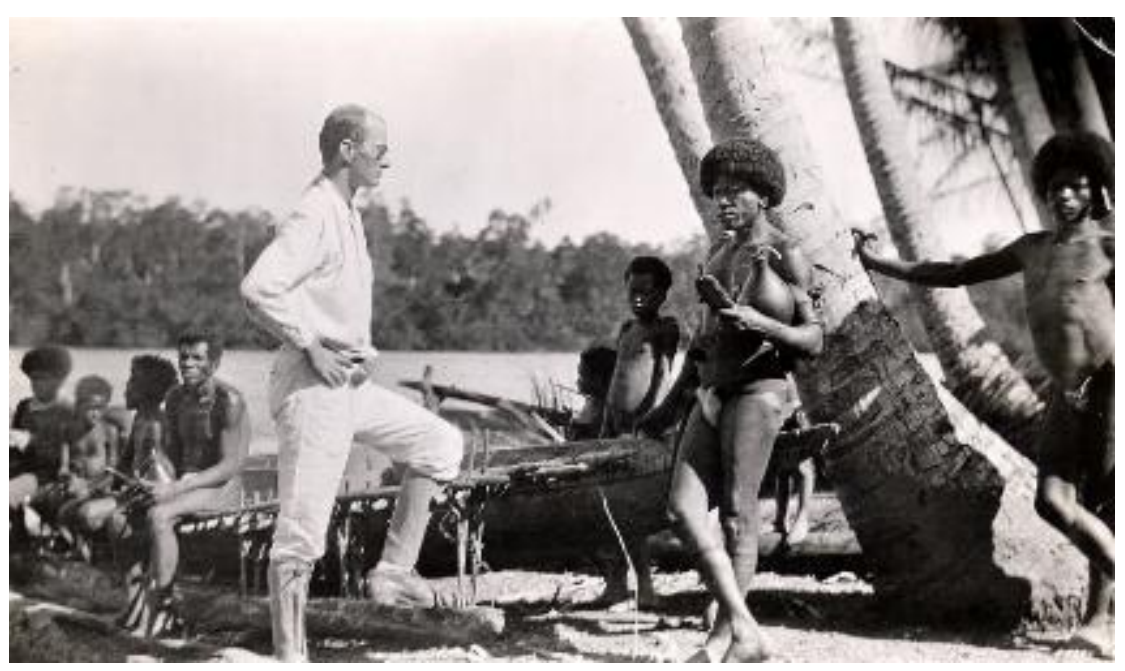

Fig. 1. Malinowski en las islas Trobriand.

Fuente: https://actividadantropologica.com/2020/10/04/documental-malinowski-y-las-islastrobriand/. Recuperado 5/03/2021. 
Si observamos las tomas publicadas por Malinowski en su obra pionera (Malinowski, 1986), a la sazón manual de trabajo para generaciones de antropólogos, vemos la necesidad de dar cuenta del "estar ahí". A decir de Stocking (2002), el lector ve lo que ve porque la autoridad del etnógrafo ha estado en ese lugar y ha traído un triunfo material en forma de artefactos. La imagen es prueba de verdad y veracidad.

Pero, además, volviendo a Benjamin (1989), la foto produce un shock, pues sirve para encontrarnos con una realidad que nos conmueve y nos aparta de una mirada distraída, propia de los flâneurs del París decimonónico que él analizaba. Y este shock, si retomamos una mirada más actual, se puede reinterpretar en clave foucaultiana (Foucault, 1987) como una generación de imágenes ante las que el público se ve en la necesidad de seleccionar e interpretar. Al fin y al cabo, si para los situacionistas estamos ante una sociedad del espectáculo (Debord, 1999), la antropología también se ha hecho eco, acudiendo al término de "teatrocracia" (Balandier, 1994) para desvelar cómo el poder se manifiesta, se representa, se dramatiza, se publica y se publicita a través de los medios.

Pero estos poderes políticos requieren también cierto componente técnico y científico para desarrollarse. Es ahí donde la labor de la ciencia social cobra relevancia. Desde los años 60 , diversos departamentos de universidades estadounidenses han desarrollado actividades para la generación e implementación de políticas públicas. Por ello, la época no podría ser más interesante para la disciplina, que en su devenir ya ha asumido diversas rupturas. Primero, desde el feminismo ha surgido el debate en torno a si las observaciones realizadas por un hombre o una mujer varían en cuanto a sus resultados. La respuesta, hoy obvia, es que sí; pero corrieron ríos de tinta en torno a uno de los debates más fructíferos, como fue el desarrollado por Margaret Mead (1961) y Freeman (1983), quien al igual que la autora de Adolescencia y cultura en Samoa también investigó a las samoanas, llegando a conclusiones diferentes. Sin entrar en el debate, donde nos situamos en el situacionismo feminista, observemos cómo la mirada cambia con respecto a lo propuesto por la generación anterior si hacemos caso de la siguiente escena:

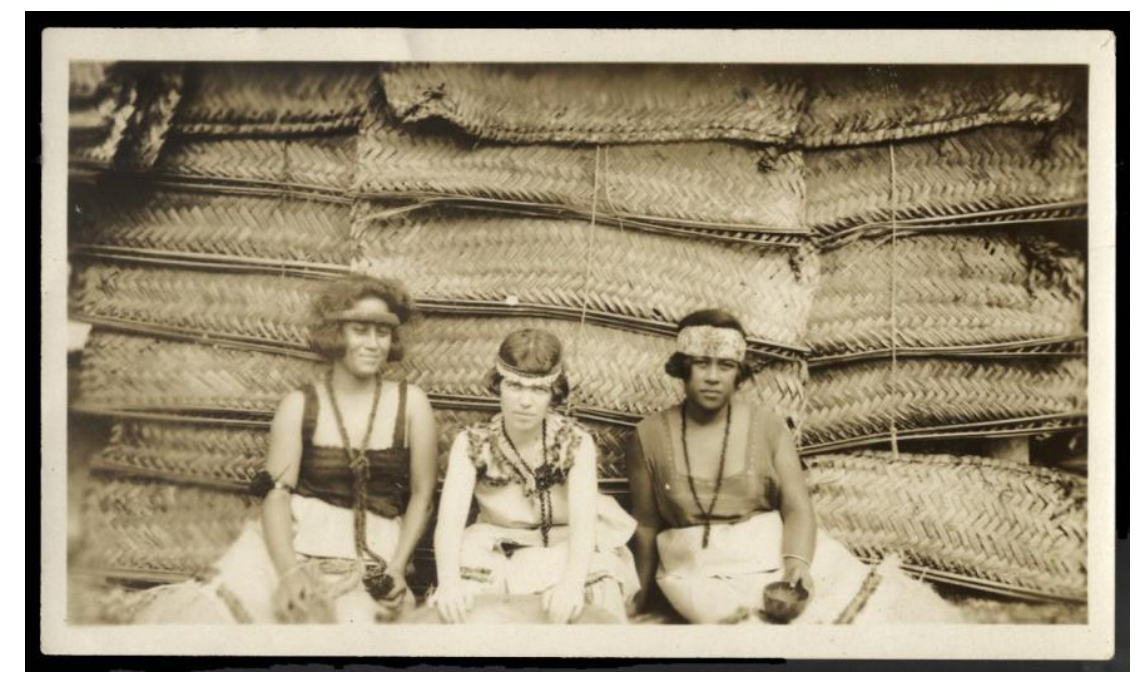

Fig. 2. Margaret Mead en Samoa.

Fuente: http://urbanalogia.blogspot.com/2018/02/15-fotos-de-margaret-mead.html. Recuperado $5 / 03 / 2021$.

La antropóloga, al igual que las nativas, mira a la cámara en el mismo plano que ellas, con similares vestimentas. Ya no se trata de esa imagen de autoridad de Malinowski que recoge notas al pie de su tienda, sino que parece una imagen de acompañamiento. El autor, padre fundador de la antropología británica, se coloca a la espera de que sus "objetos" de investigación le cuenten algo; él es el único que no mira a la cámara. Si el feminismo ha generado debates fructíferos en la época antibelicista señalada (no olvidemos la acusación a la disciplina de ser hija del colonialismo), otro hilo de ruptura con la época clásica y con el funcional-estructuralismo lo tenemos en la llamada crítica a la autoridad etnográfica. 
La aparición póstuma de los diarios de Malinowski dio un empujón a esto, por cuanto, a decir de Geertz (1989), supuso la muerte del sumo sacerdote. Si en Los argonautas aparecía la imagen de un científico objetivo, neutral, aséptico; en Los diarios aparecían relatos íntimos, reflexivos, críticos con su situación y con los sentimientos que le deparaba un contexto extraño. Se producía, con unos 40 años de distancia entre ambas publicaciones, una ruptura con la objetividad por parte de su principal defensor; una crisis que hizo repensar metodológicamente, pero también ética, política y epistemológicamente, las relaciones "objetos-sujeto", incluso llegando a criticarse la propia noción de "informante".

\section{Imaginando al "Otro"}

Para esa crítica a la autoridad situemos dos acontecimientos: la aparición de una generación post-Geertz, que debatía las relaciones etnógrafo-informante (Reynoso, 2003); y un nuevo debate surgido en un contexto poscolonial. Nos referimos a la publicación de Islas de Historia de Marshall Sahlins (1988) y su debate con un antropólogo nativo, Obeyesekere (Osorio, 1997; Andrade, 2004). Si antes nos preguntábamos si las observaciones tomadas por personas de género diferente (y aquí, al dualismo varón-mujer habría que sumar hoy el colectivo LGTBI+ y las críticas surgidas desde diversos feminismos como el chicano, el musulmán, el negro, el gitano, el indígena, la teoría queer, etc.) podrían llevar a interpretaciones diversas, en esta época la pregunta es si lo observado por un científico nativo no diferirá de los datos obtenidos por alguien externo al grupo. El debate sirvió para reinterpretar la división emic-etic, y para nuestro caso nos sirve para descentrar dos aspectos en torno a la imagen y su implicación para la disciplina. Observemos la siguiente figura:

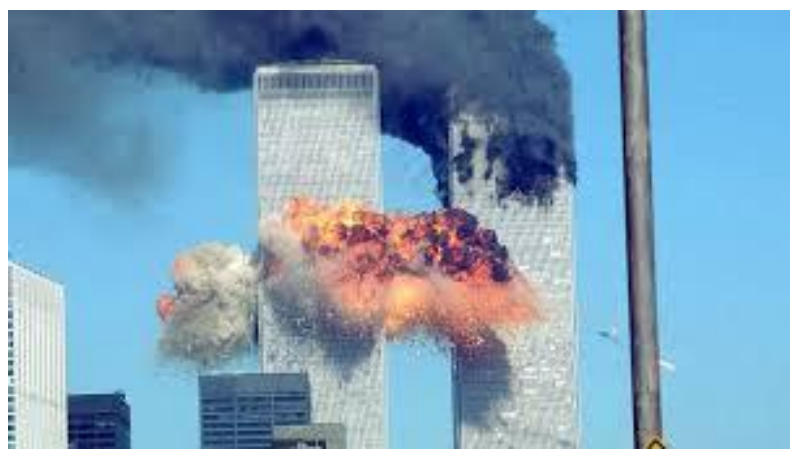

Fig. 3. Torres Gemelas.

Fuente: https://www.bbc.com/mundo/noticias-40869291. Recuperado 5/03/2021.

Se trata de una fotografía de prensa, pero si la hubiese tomado algún antropólogo seguramente sería similar. Chéroux (2007, p. 55) se pregunta ¿qué hemos visto el 11-S? y lo cierto es que la respuesta no puede inquietarnos más: "siempre lo mismo". Las agencias de todo el mundo repitieron las mismas imágenes durante semanas: "imágenes en bucle, siempre las mismas, tartamudeadas por un ejército de speakers", a decir de Jean-Luc Godard, citado por Chéroux (2007). Esto nos plantea dos interrogantes: ¿la reiteración del espectáculo, hasta qué punto podría ser emancipatoria?, lo cual conecta con Benjamin (1989), que veía como una apertura a la clase obrera el democratizar el arte y combatir las formas estéticas del fascismo; y en segundo lugar, ¿qué puede decir esa pérdida de autoridad del científico (o en este caso del reportero o del etnógrafo) hacia la aparición de nuevas formas de comprender las imágenes? Nos referimos aquí a dos conceptos que van de la mano: la muerte del autor y la consiguiente aparición masiva del público; y la generación de lo que Foster (2001) denomina el artista como etnógrafo. En cualquier caso, la salida de la tienda de campaña y la proliferación de escenarios de complejidad etnográficos es más patente que nunca en la sociedad de la vigilancia foucaultiana, donde el paisaje está impregnado de cámaras por doquier. 
Primero Barthes (1987) y después Foucault (1987) analizan qué supone la muerte del autor. Dice Barthes $(1987$, p. 3) que "la escritura es la destrucción de toda voz, de todo origen", siendo el autor un personaje de la Modernidad occidental donde "el escritor se limita a imitar un gesto siempre anterior, nunca original". Y es que si seguimos la lógica nietzscheana según la cual no hay hechos, sólo interpretaciones, no es baladí la profusión que tuvo por parte de Geertz (2000) y el interpretativismo el resaltar que vivimos en tramas de significado donde interpretamos y reinterpretamos lo que otros antes ya han interpretado. Esto lleva a Barthes (1987) a exponer que el autor ha muerto y ha sido reemplazado por el escritor, donde para nuestra disciplina es clave el mostrar qué se ha obtenido en una etnografía, que en general esconde más que muestra, ordena más que describe y genera un relato lineal a partir de narraciones en principio inconexas que solo encuentran un orden en la cabeza de quien las desarrolla. Foucault (1987) aún va más allá, exponiendo que más que de autores hay que analizar qué lleva a alguien a ser considerado como tal y, sobre todo, cambiar la lente y proponer que se trata más bien de generadores de discursividad.

Es precisamente en estos intersticios entre la autoridad del autor y la obligatoriedad de publicar y contrastar la otredad donde juega su rol la antropología, entendida como ciencia de la alteridad y la diversidad. Si bien es verdad que ya desde hace más de un siglo las acusaciones de Boas de racismo a varios de sus colegas han tenido un peso crucial en la disciplina (Stocking, 2002), observemos que desde mediados del siglo pasado estamos ante el derrumbe de lo colonial y el surgimiento de lo poscolonial y decolonial, influido por una serie de teóricos que descentran el ojo, cambian la mirada y "provincializan Europa" (Chakrabarty, 1999), generando miradas "otras". Pensemos el influjo de Fanon (2009), Césaire (2006) o Said (2007), o desde los estudios culturales el aporte de Bhabha (2007), para quien el estereotipo y el mimetismo son condiciones desde las que las relaciones de asimetría racial son constantemente enunciadas. Fijémonos para ello en la siguiente figura:

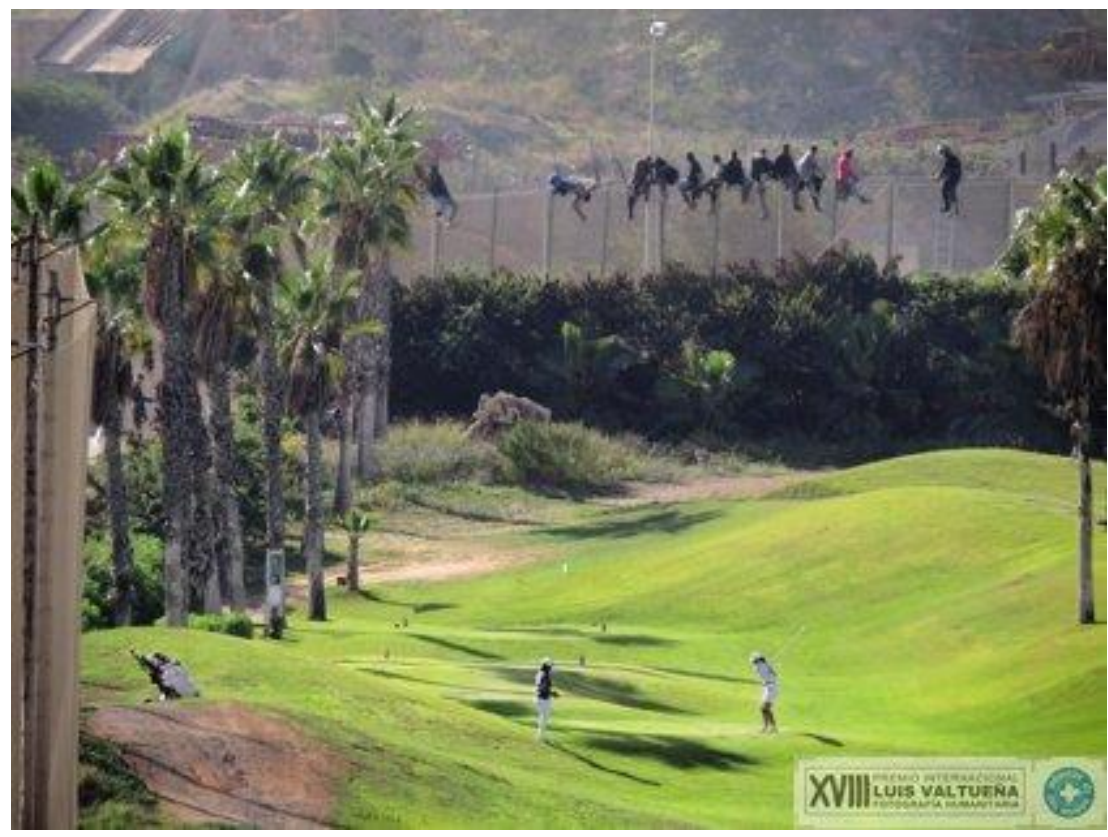

Fig. 4. Migrantes saltando la valla de un campo de golf en Melilla.

Fuente: https://m.europapress.es/epsocial/migracion/noticia-jose-palazon-prodein-premio-luisvaltuena-fotografia-valla-melilla-20141217110145.html. Recuperado 6/3/2021

Palanzón (2015), autor de esta imagen, realiza una labor de etnógrafo. Es capaz de observar, captar, analizar e interpretar visualmente las relaciones "nosotros-ellos" y condensar el fenómeno migratorio y el conflicto político en torno a las fronteras y la diversidad cultural en esta fotografía. 
Se trataría, según Pratt (2010), de una "zona de contacto" donde sobre el fondo de un "paisaje étnico" (Appadurai, 1991) aparecen, de una parte, golfistas en su tiempo de esparcimiento; y de la otra africanos encaramados en una valla tratando de saltar a Europa. El contraste, la ambigüedad y la asimetría no podrían ser más claros, temáticas todas analizadas por la antropología. El "otro", analizado como individuo del capitalismo (mercancía, mano de obra), es puesto en relación, como si de un espejo lacaniano se tratase, para construir la identidad del "nosotros" (Lacan,1992). Es ahí donde surge el estereotipo propuesto por Bhabha (2007), que tiene que ser repetido, hiperbolizado: "mira, mamá, un negro", diría Fanon (2009), criticando la dialéctica hegeliana amo-esclavo. Así pues, la antropología se imagina al "otro", pero como decimos, las imágenes también nos miran y sirven para criticar, en este caso, al multiculturalismo neoliberal, que a menudo emplea una retórica que omite y silencia las relaciones de poder y las asimetrías que sostienen la diversidad cultural. Esta imagen supone un encuentro con lo real, en sentido lacaniano, e implica una respuesta por parte del espectador, algo que ha venido buscando la antropología desde sus inicios y que desde nuestro punto de vista se consigue más efusivamente uniendo narración, inventiva, emoción, relato, imaginación e imagen que simplemente con unas etnografías malinowskianas, "objetivas" y sin voz del "otro".

\section{Conclusiones}

¿Se puede hacer observación con imágenes? ¿Se puede hacer participación con imágenes? ¿Cuál es la relación entre las palabras, las cosas y las imágenes? En un texto clásico para la antropología española, Ricardo Sanmartín (2003) exponía que la antropología se basa en observar, escuchar, comparar, escribir. Debemos agregar el mirar y ser mirados, pues ni la cámara da toda la objetividad pretendida ni existen miradas neutrales, sino que incluso el acto de fotografiar requiere cierta imaginación sociológica, antropológica y estética. Una imaginación que no puede ser confundida con la fantasía, el escapismo o la contemplación, sino que tiene que ver con cómo afrontar las nuevas relaciones entre medios culturales y seres humanos. Ver también es participar, y quizá permita responder a aquel “¿puede hablar el subalterno?" (Spivak, 2003). Sí puede, y la antropología visual da una herramienta crucial al respecto.

Tal y como hemos analizado, la antropología en las últimas décadas se ha visto atravesada por debates en torno a la manera de mirar y de representar al otro, y al mismo tiempo, de representarse a sí misma. Nuestra disciplina no solo tiene en la otredad un espejo desde el que observarse, sino que para ello puede servirse de diversas lentes. En este trabajo, hemos intentado reflexionar acerca del potencial de las imágenes, en particular de la fotografía, a la hora de captar y representar el mundo social. La imagen de la etnografía, así lo entendemos nosotros, puede y debe ser complementada con la etnografía como imagen; esto es, con la incorporación de otras miradas y otros registros visuales, que den perspectiva a la contemporaneidad y amplíen nuestro repertorio metodológico. Si desde Geertz la misión de la ciencia social no es tanto elaborar leyes sino elevar la calidad del debate académico, y si con Gadamer (2005) tenemos que un objetivo fundamental de la ciencia es ampliar y fundir horizontes, en este trabajo hemos asumido esas propuestas interpretativo-hermenéuticas, precisamente para ampliar los debates y observarlos desde/con múltiples enfoques. Es por esta razón, que nuestra propuesta conceptual del desenfoque visual etnográfico se abre a las diversas formas de mirar, sabiendo que ni existe una mirada pura ni existen interlocutores que no nos puedan devolver la mirada. Una mirada singular y compleja, que nos permite entrar y salir de lo local para situarnos en contextos de análisis más amplios, hoy globales e interconectados. 


\section{Referencias}

Alfonso, M. y Piñeiro, E. (2021). Transfronterización, sobrefronterización y desfronterización. El arte de la performance en la frontera entre Estados Unidos y México. Revista Colombiana de Sociología, 44(1), 217-235.

Alfonso, M. y Piñeiro, E. (2016). Representaciones interculturales del exilio. Los usos de la videoperformance del artista-Prometeo Fernando Baena. Kamchatka, 129, 149.

Andrade, Gabriel (2004) Observaciones sobre el debate Sahlins-Obeyesekere: la muerte del capitán Cook vista desde la antropología de René Girard. Revista de Ciencias Sociales X (1), 101-111.

Appadurai, A. (1991). Global Ethnoscapes. Notes and Queries for a Transnational Anthropology. En R. Fox, (ed.) Recapturing Anthropology. Working in the Present (pp. 191-210). School of American Research Press

Aznar, Y., \& López Díaz, J. (2019). Arte desde los setenta: Prácticas en lo político. Editorial Centro de Estudios Ramón Areces.

Balandier, G. (1994). El poder en escenas. Paidós.

Barthes, R. (1987). La muerte del autor. Paidós.

Benjamin, W. (1989). La obra de arte en la época de su reproductibilidad técnica. Discursos interrumpidos $I, 15-57$.

Bhabha, H. (2007). El lugar de la cultura. Manantial.

Chakrabarty, D. (1999). La poscolonialidad y el artilugio de la historia: ¿quién habla en nombre de los pasados 'indios'? Pasados poscoloniales, 441-471.

Chéroux, C. (2007) ¿Qué hemos visto del 11 de septiembre? En Didi-Huberman, G., Chéroux, C. y Arnaldo, J. (2007) Cuando las imágenes tocan lo real. Círculo de Bellas Artes.

Césaire, A. (2006). Discursos sobre el colonialismo. Ediciones Akal.

Clifford, J. (1995). Dilemas de la cultura. Gedisa.

Clifford, J. y Marcus, G. (1991). Retóricas de la antropología. Júcar.

Debord, G. (1999). La sociedad del espectáculo. Pre-textos.

Didi-Huberman, G., Chéroux, C. y Arnaldo, J. (2007) Cuando las imágenes tocan lo real. Círculo de Bellas Artes.

Diz, C. (2011). Los caminos del clown: resistencia en movimiento. Juego, carnaval y frontera. Athenea Digital. Revista de pensamiento e investigación social, 11(2), 157-171

Fanon, F. (2009). Piel negra, máscaras blancas. Ediciones Akal.

Foster, H. (2001). El artista como etnógrafo. En H. Foster El retorno de lo real. Akal: 175-207.

Foucault, M. (1987). ¿Qué es un autor? Revista de la Universidad Nacional, 2(11), 4-19.

Fox, R. (ed.) Recapturing Anthropology. Working in the Present. Santa Fe: School of American Research Press.

Freeman, D. (1983). Margaret Mead and Samoa: The Making and Unmaking of an Anthropological Myth. Harvard University Press.

Gadamer, H. (2005). Verdad y método. Ediciones Sígueme.

Geertz, C. (2000). La interpretación de las culturas. Gedisa.

Geertz, C. (1989). El antropólogo como autor. Paidós.

Gómez, Carlos (2012) (ed.) Doce Textos fundamentales de la ética del siglo XX. Alianza.

Grosfoguel, R. (2016). Del «extractivismo económico» al «extractivismo epistémico» y al «extractivismo ontológico»: una forma destructiva de conocer, ser y estar en el mundo. Tabula Rasa, (24), 123-143. 
Lacan, J. (1992). El revés del psicoanálisis. Paidós.

Lisón Tolosana, C. (2001). Antropología: Horizontes interpretativos. Universidad de Granada.

Malinowski, B. (1986). Los argonautas del Pacífico occidental. Planeta.

Malinowski, B. (1989). Diario de campo en Melanesia. Júcar.

Mead, M. (1961). Adolescencia y cultura en Samoa. Paidós.

Molina, R., y Piñeiro, E. (2017). Fotografía y comunicación intergeneracional en la recuperación de la memoria histórica y fortalecimiento de la identidad cultural. Revista San Gregorio, 19, 4453

Osorio, F. (1997). Hegel y la Muerte del Capitán Cook. Cinta de Moebio, 1, 77-86.

Pratt, M. (2010). Ojos imperiales. Fondo de Cultura Económica.

Reynoso, C. (ed.). El surgimiento de la antropología posmoderna. Gedisa.

Sahlins, Marshall (1988). Islas de Historia: La muerte del capitán Cook, Metáfora, antropología e historia. Gedisa.

Said, E. W. (2007) Orientalismo. DeBolsillo.

Sanmartín, R. (2003). Observar, escuchar, comparar, escribir. Ariel.

Spivak, G. (2003). ¿Puede hablar el subalterno? Revista Colombiana de Antropología, 39, 297364.

Stocking, G. (2002). Delimitando la antropología. Revista de Antropología Social, 11, 011-038. 